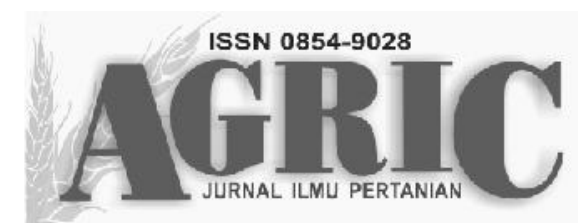

Fakultas Pertanian dan Bisnis Universitas Kristen Satya Wacana Jl. Diponegoro 52-60 SALATIGA 50711 - Telp. 0298-321212 ext 354

email: agric_fpb@yahoo.co.id, website: ejournal.uksw.edu/agric

\title{
OPTIMALISASI PEMANFAATAN SUMBER DAYA HAYATI RAMBUTAN KELENGKENG DESA KARANGREJO, BOROBUDUR KABUPATEN MAGELANG MELALUI OKULASI
}

\section{OPTIMIZATION OF RESOURCE CONSERVATION OF LONGAN-RAMBUTAN OF KARANGREJO VILLAGE, BOROBUDUR, MAGELANG DISTRICT THROUGH GRAFTING TEHCNIQUES}

\author{
Nugraheni Widyawati \\ Program Studi Agroteknologi Fakultas Pertanian dan Bisnis \\ Universitas Kristen Satya Wacana \\ heniwidya@gmail.com \\ Lasmono Tri Sunaryanto \\ Program Studi Agroteknologi Fakultas Pertanian dan Bisnis \\ Universitas Kristen Satya Wacana \\ Djoko Murdono \\ Program Studi Agroteknologi Fakultas Pertanian dan Bisnis \\ Universitas Kristen Satya Wacana \\ Diterima 3 November 2016, disetujui 5 Desember 2016
}

\begin{abstract}
Karangrejo village, subdistrict of Borobudur, Magelang regency has Punthuk Setumbu as a very beautiful place to watch the sunrise from the peak of Mounts Merapi and Merbabu with Borobudur shadow in the foreground. Beside its famous sunrise view, Karangrejo also famous with its rambutan fruit with trees nearly at every home yard. From pre-findings activities, there was a certain good rambutan variety that they called "rambutan klengkeng" or longan-rambutan. This special kind of rambutan is so sweet, with thick flesh, easy to peel and fresh longer. It has potential to develop it as "Rambutan Karangrejo" as a special local type that become identity and source of income of Karangrejo villagers. The main objective of this activity are: (1) to identify the potentiallity of longan rambutan superior characteristics; (2) to improve the ability of farmers group to multiply the longan rambutan trees through grafting techniques. The method used were survey, focus group discussions, training, demonstration, self practicing and mentoring. The results are: 1. Some fruits that potential to develop are include rambutan, banana and jackfruit. Longan Rambutan fruit have many good characteristics such as its taste, thickness of flesh fruit, flavor, easy to peel and fresh longer. 2. The training for grafting technique have improved the understanding and skills of farmers group in terms of preparing rootstock, eye patch, prepare materials and tools, performing grafting techniques, monitoring and caring the grafting tress.
\end{abstract}

Keywords: longan-rambutan, local speciality, grafting 


\section{PENDAHULUAN}

Pohon rambutan termasuk salah satu jenis tanaman buah tropis yang sangat cocok dikembangkan di Indonesia dan mempunyai nilai ekonomi cukup bagus. Duchlun dkk (2006) menganalisis usahatani rambutan dalam kaitannya dengan peningkatan pendapatan petani, menyimpulkan bahwa hasil analisis ekonomi dengan luas lahan rata-rata 1 ha selama 5 tahun penerimaan rata-rata $\mathrm{Rp} 24.120 .000$, dengan pendapatan rata-rata $R p 29.959 .595$ per 5 tahun atau Rp 499.326 per bulan dan R/C Ratio 3,46, hal ini menunjukkan bahwa usahatani rambutan layak untuk dikembangkan oleh petani. Petani rambutan masih perlu dibina secara kontinyu terutama dalam hal teknik budidaya rambutan yang baik dan benar.

Tanaman ini termasuk dalam suku lerak-lerakan atau Sapindaceae, genus Nephelium, spesies Nephelium lappaceum L. Varietas unggul rambutan yang sudah dilepas Departemen Pertanian Republik Indonesia hingga 2005 adalah 1. 'Rapiah' dari Pasar minggu, 2. 'Bahrang' dari Langkat, 3. 'Lebak bulus' dari Pasar minggu, 4. 'Sibatuk Ganal' dari Sungai Andai, Kalimantan Selatan, 5. 'Nona' dari Kampar, Riau, 6. 'Binjai' dari Pasar minggu 7. 'Antalagi' dari Sungai Andai, Kalimantan Selatan, 8. 'Sibongkok' dari Sungai Luhut, Kalimantan Selatan, 9. 'Garuda' dari Sungai Andai, Kalimantan Selatan 10. 'Tangkue Lebak' dari Kecamatan Maja, Banten, 11. 'Narmada' dari NTB.

Selain dikonsumsi karena kandungan vitamin C, mineral dan seratnya, rambutan mempunyai beberapa fungsi lain yang masih dalam penelitian dan pengkajian. Rahayu dkk (2013) menyebutkan bahwa Rambutan (Nephelium lappaceum L.) merupakan salah satu tanaman yang dapat digunakan untuk mengobati berbagai macam penyakit, salah satunya diabetes melitus. Rosahdi dkk (2013) menyebutkan bahwa buah rambutan memiliki kandungan antioksidan yang tinggi. Toksisitas yang rendah dari senyawa antioksidan yang berasal dari bahan alam menyebabkan senyawa ini lebih diminati dibandingkan dengan senyawa sintetik Ibrahim dkk (2013) meneliti efektifitas biji rambutan sebagai anti bakteri, hasilnya adalah bahwa konsentrasi minimal yang efektif untuk menghambat pertumbuhan tiga bakteri patogen (Aeromonas hydrophila, A. Salmonicida dan Streptococcus sp) adalah pada konsentrasi 50-75\% dan semakin tinggi konsentrasinya menunjukkan kandungan bahan aktif flavonoid dalam biji rambutan semakin berfungsi sebagai anti bakteri patogen pada ikan. Issara dkk (2014) menyebutkan bahwa biji rambutan mengandung kadar lemak yang tinggi dan jenis lemaknya seperti pada buah cocoa, sehingga sering digunakan dalam industri permen. Buah rambutan bisa diolah menjadi selai seperti hasil penelitian dari Afrina (2012), sementara Lesmayati (2014) mengolah buah rambutan menjadi sirup. Buah rambutan dewasa ini juga sering diolah menjadi dodol rambutan.

Masyarakat desa Karangrejo, Kecamatan Borobudur, Magelang, mempunyai banyak pohon rambutan dan salah satu diantaranya mereka sebut sebagai rambutan kelengkeng, karena ada kemiripannya dengan kualitas kelengkeng batu. Namun sejauh ini masyarakat di desa tersebut belum bisa memanfaatkannya dengan baik karena sebagian besar hanya dikonsumsi sendiri dan tanpa pemeliharaan yang berarti. Asal usul jenis rambutan ini masih belum jelas karena mereka membeli bibit dari pedagang yang datang ke desa.

Melihat potensi yang cukup besar untuk dikembangkan lebih lanjut, maka perlu dilakukan identifikasi dan peningkatan populasi jenis rambutan tersebut. Salah satu cara yang efektif dan tidak menurunkan kualitas buahnya adalah perbanyakan vegetatif baik secara okulasi maupun sambung. Cara okulasi seringkali 
menjadi pilihan karena calon batang atas hanya berasal dari mata tunas, sehingga tidak mengambil organ tanaman dalam jumlah banyak. Mata tunaspun lebih ringkas untuk dibawa dalam jarak tertentu dalam keadaan masih baik. Masalahnya adalah masyarakat desa ini belum paham dan tidak memiliki ketrampilan untuk memperbanyak pohon rambutan secara okulasi. Jelaslah bahwa pelatihan tentang ketrampilan memperbanyak pohon rambutan kelengkeng secara okulasi masih diperlukan oleh masyarakat desa Karangrejo.

Tujuan dari kegiatan pemberdayaan masyarakat ini adalah:

(1) Mengidentifikasi potensi sumberdaya hayati tanaman buah dan sifat unggul rambutan kelengkeng.

(2) Meningkatkan kemampuan kelompok dalam mengembangbiakkan jenis rambutan kelengkeng melalui teknik okulasi.

\section{METODE PENELITIAN}

\section{Waktu dan Lokasi Kegiatan}

Kegiatan pemberdayaan masyarakat untuk mengoptimalkan pemanfaatan kekayaan sumberdaya hayati pohon rambutan ini dilakukan pada bulan Maret hingga Nopember 2016. Kegiatan dilakukan di desa Karangrejo, Kecamatan Borobudur, Kabupaten Magelang. Lokasi kegiatan terletak pada elevasi $150 \mathrm{~m}$ dpl hingga $300 \mathrm{~m}$ dpl dengan suhu rata rata hariannya $28^{\circ} \mathrm{C}$. Kelembaban udara di wilayah tersebut termasuk kategori sedang.

\section{Sasaran Kegiatan}

Dalam kegiatan pemberdayaan masyarakat ini, khalayak sasaran adalah anggota kelompok tani yang terorganisasi dalam Perkumpulan Petani Organik Sumber Makmur (PPOSM). Kelompok tani ini dipilih karena telah memiliki kegiatan yang relatif rutin dan memiliki keinginan untuk memajukan desa. Jumlah anggota kelompok tani ini ada 20 orang da telah mempunyai ketua, sekretaris, dan bendahara.

\section{Metode Pelaksanaan}

Kegiatan pemberdayaan masyarakat ini dilakukan menggunakan metode gabungan survei, FGD, pelatihan, praktik mandiri dan pendampingan dan studi pustaka.

Survei dilakukan untuk mengetahui jenis pohon buah yang potensial dikembangkan, kemampuan masyarakat memanfaatkan pohon rambutan yang mereka miliki, mengidentifikasi jenis rambutan yang potensial dikembangkan, menjaring calon peserta pemberdayaan. Jumlah responden dalam survey 20 kepala keluarga.

Penyuluhan dilakukan untuk memberikan pemahaman tentang perlunya mengoptimalkan sumberdaya lingkungan termasuk didalamnya sumber daya hayati agar bisa menambah penghasilan masyarakat.

Pelatihan dilakukan untuk meningkatkan ketrampilan dalam melakukan okulasi, melalui tahapan: penyiapan modul, penyiapan lokasi, bahan dan peralatan serta penjadwalan dan pelaksanaan kegiatan pelatihan.

Praktek mandiri dilakukan setelah kegiatan pelatihan untuk meningkatkan ketrampilan individu. Pendampingan dilakukan sepanjang berjalannya kegiatan, untuk memecahkan permasalahan dan mengevaluasi hasil kegiatan. Studi pustaka terutama untuk tujuan pembuatan modul pelatihan agar dapat digunakan secara berkelanjutan.

\section{Metode Evaluasi Kegiatan}

Untuk membahas hasil kegiatan dilakukan dengan penyajian data deskriptif kualitatif maupun kuantitatif disertai dengan studi pustaka.

\section{HASIL DAN PEMBAHASAN}

\section{Gambaran Umum dan Potensi Wisata Desa Karangrejo}

Karangrejo adalah nama sebuah desa yang 
terletak di kecamatan Borobudur, Kabupaten Magelang, Provinsi Jawa Tengah, Indonesia. Desa Karangrejo memiliki 6 dusun yaitu: Kretek I; Kretek II; Sendaren 1; Sendaren 2; Bumen Djelapan dan Kurahan. Jarak desa ini dengan pusat Pemerintahan Kecamatan Borobudur sekitar 2-3 km. Luas wilayah desa sekitar 174 ha, terdiri atas lahan sawah dan ladang (sekitar 98 ha) dan sisanya adalah pemukiman serta fasilitas umum. Topografi desa mulai dari landai hingga berbukit dengan elevasi 200 meter dpl hingga lebih dari 400 meter dpl. Wilayah berbukit masih termasuk dalam gugusan bukit Menoreh. Warga desa Karangrejo bekerja di sektor pertanian dan jasa, yaitu sebagai petani, buruh tani, pedagang asongan, jasa pariwisata (pemandu wisata), fotografer, transportasi, penjaga keamanan dan tenaga kebersihan hotel (Anonim, 2012). Jalan utama desa sudah permanen dengan pengaspalan sederhana dan sebagian rumah yang berada di tepi jalan mulai difungsikan juga sebagai homestay bagi pengunjung yang hendak menikmati keindahan sunrise dari Punthuk Setumbu.

Konon potensi wisata desa Karangrejo mulai ditemukan pada tahun 2000 an oleh seorang photografer yang mengabadikan pemandangan sunrise yang sangat eksotik dari ketinggian bukit (sekitar 400 meter dpl.) yang disebut bukit Punthuk Setumbu. Seiring dengan berjalannya waktu, dibantu oleh berbagai pihak dan adanya partisipasi warga, maka bukit Punthuk Setumbu dipopulerkan sebagai salah satu tujuan wisata untuk menyaksikan sunrise dengan latar belakang gunung Merbabu dan Merapi serta Candi Borobudur. Sofianto (2013) menyebutkan bahwa pengelolaan Punthuk Setumbu pada masa yang akan datang memerlukan perbaikan dan penataan yang serius serta keterkaitan dengan berbagai unsur wisata lain di desa agar bisa berjalan dengan sinergis.

Selain bukit Punthuk Setumbu, desa ini juga memiliki sebuah bukit yang disebut Bukit Rhema.
Keindahan bukit Rhaema terutama karena dipuncak bukit ini terdapat sebuah gedung yang disebut masyarakat sebagai Gereja Ayam. Sebutan ini populer dikarenakan bentuk bangunan gereja tersebut menyerupai ayam dan jika dilihat dari udara nampak seperti seekor burung raksasa yang berada di tengah rimbunan hutan, karena bukit itu memang masih rimbun dengan pepohonan. Konon sebenarnya bentuk yang diinginkan adalah seekor burung Merpati, namun karena terlihat lebih menyerupai seekor ayam maka gereja tersebut populer sebagai Gereja Ayam. Bukit Rhema akhir akhir ini semakin populer dengan Gereja Ayam dan pemandangan sekitarnya karena digunakan sebagai lokasi syuting film Ada Apa Dengan Cinta (AADC).

Berkaitan dengan potensi wisata desa Karangrejo, dalam penelitiannya Sofianto (2013) menyebutkan bahwa semakin banyak wisatawan, terutama wisatawan asing berkunjung ke desa tersebut, memberikan harapan bagi warga desa untuk meningkatkan perekonomiannya. Warga dan pemerintah desa setempat mulai memikirkan penataan kunjungan wisata di Punthuk Setumbu, baik secara infrastruktur maupun kelembagaan.

\section{Sumberdaya Hayati Pohon Buah dan Karakter Rambutan Kelengkeng Desa Karangrejo}

Dari hasil survei, jumlah jenis pohon buah yang ditanam oleh masyarakat desa Karangrejo cukup banyak. Namun yang ditanam oleh responden (lebih dari 5\%,), ada sepuluh jenis pohon buah. Berbagai jenis pohon buah tersebut tidak dibudidayakan secara intensif, melainkan hanya bersifat sebagai pengisi kebun dan pekarangan rumah. Sejauh ini masyarakat Desa Karangrejo belum menggantungkan matapencahariannya dari kegiatan membudidayakan tanaman buah.

Tanaman buah tidak hanya menghasilkan organ buah yang bernilai ekonomis, melainkan juga menghasilkan sesuatu yang bernilai non 
Tabel 1 Kekayaan sumberdaya hayati pohon buah di Desa Karangrejo

\begin{tabular}{lc}
\hline \multicolumn{1}{c}{ JENIS } & PERSENTASE \\
POHON BUAH & JUMLAH RESPONDEN \\
& YG MENANAM \\
\hline Rambutan & 100,0 \\
Pisang & 66,7 \\
Nangka & 55,6 \\
Langsep & 38,9 \\
Durian & 27,8 \\
Mangga & 22,2 \\
Kelengkeng & 11,1 \\
Jeruk & 11,1 \\
Manggis & 5,6 \\
Duku & 5,6 \\
\hline
\end{tabular}

Sumber: Data Primer, 2016

ekonomis namun esensial bagi mahluk hidup dan lingkungannya, yaitu menghasilkan oksigen. Sebagai pabrik oksigen, peranan tanaman buah buahan sangat penting, apalagi jika ditanam di pekarangan sekitar rumah. Setiap orang memerlukan oksigen 0,5 kg per hari (Leaflet Dinas Pertamanan dan Pemakaman Bandung, dalam Kusminingrum, 2008). Sebuah pohon pelindung bisa memenuhi oksigen untuk dua orang (Imran, 2002 dalam Kusminingrum, 2008). Jelaslah bahwa peningkatan populasi pohon buah buahan akan menjadi sangat berguna untuk memasok oksigen udara sekitarnya, apalagi untuk sebuah desa tujuan wisata yang potensial dikunjungi banyak orang.

Tanaman buah juga bisa berfungsi sebagai elemen lansekap untuk peneduh jalan, membersihkan udara dan menimbulkan suasana sejuk. Dalam penelitian Kusminingrum (2008), terindikasi bahwa berbagai jenis pohon dapat mengurangi kadar $\mathrm{CO} 2$ ruangan sekitarnya sebesar $23,47 \%$ hingga $81,53 \%$. Pengurangan kadar $\mathrm{CO} 2$ dalam udara ini penting sekali untuk mengendalikan terjadinya pemanasan udara, apalagi untuk sebuah desa wisata yang potensial banyak kendaraan bermotor akan lalu lalang di wilayah tersebut.

Dari berbagai jenis pohon buah tersebut, menurut responden jenis yang berpotensi untuk dikem- bangkan di desa mereka adalah: Rambutan, pisang, nangka, langsep. Jenis rambutan yang ditanam di pekarangan penduduk adalah rambutan kelengkeng, rambutan binjai, rambutan rafiah. Dari jenis rambutan tersebut, yang dipilih untuk diperbanyak adalah jenis rambutan kelengkeng karena mempunyai keunggulan dalam hal rasa dan kualitas fisik buahnya. Hasil survei tentang karakter pohon rambutan kelengkeng, tercantum dalam Tabel 2.

\section{Kemampuan Masyarakat Memanfaatkan Sumberdaya Hayati Pohon Rambutan kelengkeng}

Dari hasil survei, ternyata $61,9 \%$ responden tidak bisa memperbanyak sendiri pohon buahnya, karena tidak punya ketrampilan untuk melakukannya. Sebanyak $38,9 \%$ responden menyatakan pernah memperbanyak pohon buahnya namun tidak terampil, sehingga kegiatannya tidak berkembang. Cara yang dilakukan dalam memperbanyak pohon buahnya adalah mencangkok dan dari biji yang tumbuh secara tidak sengaja. Dari hasil survei ini ternyata tidak ada responden yang bisa dan terampil melakukan perbanyakan pohon buahnya.

Dari hasil wawancara dengan responden, semua setuju untuk mengembangkan pohon rambutan kelengkeng karena memiliki keunggulan yang 
bisa diandalkan. Semua responden bersedia untuk bergabung dalam program perbanyakan bibit rambutan klengkeng yang akan diawali dengan penyediaan batang bawah. Pelatihan ketrampilan dan pengetahuan yang dipilih oleh responden yang berkaitan dengan pengembangan pohon rambutan klengkeng di desa itu adalah:
- Perbanyakan bibit secara okulasi

- Perawatan bibit

- Teknik menjual bibit.

- Pengolahan buah rambutan menjadi sirup, manisan dan dodol.

Jika telah memiliki ketrampilan memperbanyak pohon rambutan kelengkengnya, $44,4 \%$ responden

Tabel 2 Hasil Identifikasi Karakter Pohon Rambutan Kelengkeng

\begin{tabular}{|c|c|}
\hline ITEM INFORMASI & URAIAN INFORMASI \\
\hline Umur pohon & 10-20 tahun \\
\hline Diameter proyeksi tajuk & $8-10 \mathrm{~m}$ \\
\hline Tinggi pohon & $7-10 \mathrm{~m}$ \\
\hline Diameter batang pohon & $65-75 \mathrm{~cm}$ \\
\hline Asal usul pohon & Okulasi \\
\hline Asal lokasi pohon & Tidak diketahui, karena membeli dari pedagang bibit keliling. \\
\hline \multirow[t]{5}{*}{ Kondisi pohon } & Sudah menghasilkan buah 4-8 kali \\
\hline & Hasil panen yang pernah dijual Rp.250.000- Rp. 400.000 . \\
\hline & Sebagian besar dikonsumsi sendiri. \\
\hline & $\begin{array}{l}\text { Produksi: fluktuatif, belum paham penyebabnya dan model } \\
\text { fluktuasinya. }\end{array}$ \\
\hline & Tahun 2011 rusak karena abu gunung merapi meletus. \\
\hline \multirow[t]{10}{*}{ Karakter Buah } & Bentuk mendekati bulat \\
\hline & Panjang : $3,5 \mathrm{~cm}$ \\
\hline & Kulit buah : berambut \\
\hline & Ketebalan kulit buah : sedang \\
\hline & Warna kulit buah ketika matang: orange \\
\hline & $\begin{array}{l}\text { Rasa daging buah : masih hijau sudah manis, ketika matang } \\
\text { rasanya manis legit, daging buahnya kisat. }\end{array}$ \\
\hline & Ketebalan buah : termasuk tebal $\pm 1 \mathrm{~cm}$ \\
\hline & Kelekatan daging dgn biji : sangat ngelotok. \\
\hline & Ukuran dan bentuk biji : kecil, agak bulat. \\
\hline & Aroma daging buah : khas rambutan. \\
\hline Musim panen & Pebruari- Maret \\
\hline \multirow[t]{5}{*}{ Karakter tajuk dan daun } & Rimbun \\
\hline & Panjang daun dewasa : $15-20 \mathrm{~cm}$ \\
\hline & Lebar bagian tengah daun : 7-10 cm \\
\hline & Bentuk daun : oval \\
\hline & Warna daun dewasa: hijau gelap \\
\hline \multirow[t]{2}{*}{ Musuh alami pohon } & Hama : Ulat kilan, lalat buah. \\
\hline & Penyakit : karat daun, lumut kerak. \\
\hline \multirow[t]{2}{*}{ Hasil panen } & Dikonsumsi sendiri, sebagian dijual ke tengkulak (ditebas) \\
\hline & $\begin{array}{l}\text { Harga jual rambutan kelengkeng bisa } 3 \text { kali hara rambutan } \\
\text { rafiah }\end{array}$ \\
\hline Pengolahan hasil panen & Tidak ada \\
\hline Perawatan & Mengikuti tanaman yang ditanam di bawahnya \\
\hline
\end{tabular}

Sumber: Data Primer, 2016 
ingin membuatnya untuk ditanam sendiri di pekarangan mereka. Sebanyak 50\% responden menginginkan untuk membuat kebun bibit kelompok, kemudian dijual dikelola bersama. Sementara sebanyak $5,6 \%$ responden berkeinginan untuk membuat bibit kemudian dijual sendiri.

Dari responden yang memiliki pohon rambutan kelengkeng yang pernah berbuah, sebanyak $66,7 \%$ yang pernah punya pengalaman menjual hasil panennya dan 33,3\% responden tidak memiliki pengalaman menjual hasil pohon rambutan kelengkengnya. Mereka mengkonsumsi hasil dari pohon itu untuk keluarga dan sanak saudaranya. Dari responden yang pernah menjual hasil pohon rambutan kelengkengnya, 50\% mereka menjualnya ke tengkulak dengan cara di tebas, sementara $50 \%$ yang lain menjualnya langsung ke pasar. Harga jual dari rambutan kelengkengnya lebih tinggi dari jenis rambutan lainnya, bahkan bisa tiga kali lipat harganya.

Selain produksi bibit rambutan kelengkeng, keinginan masyarakat untuk mampu mengolah hasil panen rambutannya sangat kuat, terutama di kalangan wanita. Hal ini disebabkan oleh banyaknya buah yang dihasilkan pada masa panen raya sebagian ada yang tidak termanfaatkan dengan baik. Melalui ketrampilan mengolah buah rambutan, diharapkan dapat memberikan tambahan penghasilan. Hastuti dkk (2013) menyebutkan bahwa pengolahan buah rambutan menjadi manisan merupakan salah satu alternatif pengolahan yang mempunyai keuntungan antara lain lebih awet, ringan, volume menjadi lebih kecil sehingga mempermudah pengemasan.

Tabel 3 Pemahaman anggota kelompok tentang kelebihan dan kelemahan teknik okulasi sebagai cara mengembangbiakkan tanaman buah

\begin{tabular}{|c|c|c|c|c|c|c|}
\hline \multirow[b]{2}{*}{$\begin{array}{c}\text { MATERI } \\
\text { PERTANYAAN }\end{array}$} & \multicolumn{3}{|c|}{ Sebelum Pelatihan } & \multicolumn{3}{|c|}{ Setelah Pelatihan } \\
\hline & $\begin{array}{c}\% \\
\text { Belum } \\
\text { pernah }\end{array}$ & $\begin{array}{c}\% \\
\text { Pernah }\end{array}$ & $\begin{array}{c}\% \\
\text { Sering }\end{array}$ & $\begin{array}{c}\% \\
\text { Belum } \\
\text { pernah }\end{array}$ & $\begin{array}{c}\% \\
\text { Pernah }\end{array}$ & $\begin{array}{c}\% \\
\text { Sering }\end{array}$ \\
\hline $\begin{array}{l}\text { Apakah anda } \\
\text { pernah melakukan } \\
\text { okulasi }\end{array}$ & 83,33 & 16,67 & 0 & 33,33 & 66,67 & 0 \\
\hline \multirow[b]{2}{*}{$\begin{array}{c}\text { MATERI } \\
\text { PERTANYAAN }\end{array}$} & \multicolumn{3}{|c|}{ Sebelum Pelatihan } & \multicolumn{3}{|c|}{ Setelah Pelatihan } \\
\hline & $\begin{array}{c}\% \\
\text { Tidak } \\
\text { tahu }\end{array}$ & $\begin{array}{c}\% \\
\text { Tahu } \\
\text { sedikit }\end{array}$ & $\begin{array}{c}\% \\
\text { sangat } \\
\text { Mengetahui }\end{array}$ & $\begin{array}{c}\% \\
\text { Tidak } \\
\text { tahu }\end{array}$ & $\begin{array}{c}\% \\
\text { Tahu } \\
\text { sedikit }\end{array}$ & $\begin{array}{c}\% \\
\text { sangat } \\
\text { Mengetahui }\end{array}$ \\
\hline \multirow[t]{2}{*}{$\begin{array}{l}\text { Apakah anda } \\
\text { mengetahui } \\
\text { kelebihan dan } \\
\text { kelemahan } \\
\text { tanaman buah } \\
\text { hasil okulasi }\end{array}$} & 83,33 & 16,67 & 0,00 & 16,67 & 50,00 & 33,33 \\
\hline & \multicolumn{3}{|c|}{ Sebelum Pelatihan } & \multicolumn{3}{|c|}{ Setelah Pelatihan } \\
\hline $\begin{array}{c}\text { MATERI } \\
\text { PERTANYAAN }\end{array}$ & $\begin{array}{c}\% \\
\text { Tidak } \\
\text { tahu }\end{array}$ & $\begin{array}{c}\% \\
\text { Tahu } \\
\text { sedikit }\end{array}$ & $\begin{array}{c}\% \\
\text { sangat } \\
\text { Mengetahui }\end{array}$ & $\begin{array}{c}\% \\
\text { Tidak } \\
\text { tahu }\end{array}$ & $\begin{array}{c}\% \\
\text { Tahu } \\
\text { sedikit }\end{array}$ & $\begin{array}{c}\% \\
\text { sangat } \\
\text { Mengetahui }\end{array}$ \\
\hline $\begin{array}{l}\text { Apakah anda } \\
\text { mengetahui alat } \\
\text { dan bahan untuk } \\
\text { melakukan } \\
\text { okulasi }\end{array}$ & 58,33 & 41,67 & 0,00 & 0 & 0 & 100 \\
\hline
\end{tabular}

Sumber: Data Primer, 2016 


\section{Evaluasi Kegiatan Pelatihan Teknik Okulasi}

Untuk mengevaluasi perkembangan pengetahuan anggota kelompok yang mengikuti pelatihan teknik okulasi, dilakukan melalui pengisian kwesioner sebelum dan setelah pelatihan. Informasi perkembangan pengetahuan anggota kelompok tersebut disajikan dalam Tabel 3.

Dalam Tabel 3, terlihat bahwa sebagian besar anggota kelompok belum pernah melakukan perbanyakan bibit tanaman buah dengan cara okulasi. Separuh dari anggota kelompok tidak mengetahui alat dan bahan yang perlu disiapkan untuk melakukan okulasi dan separuh anggota yang lainnya mengetahui namun hanya sedikit. Setelah dilakukan pelatihan, persentase anggota yang pernah melakukan okulasi meningkat dan semuanya mengetahui bahan serta alat yang digunakan untuk melakukan okulasi. Peningkatan persentase jumlah anggota yang pernah melakukan okulasi ini terjadi karena separuh dari anggota yang hadir mempraktikkan teknik okulasi yang diajarkan. Dari jawaban para peserta pelatihan terlihat bahwa walaupun sudah diberikan pelatihan yang disertai dengan praktik, namun tetap saja ada peserta yang hanya mendengarkan tutorial $(33,3 \%)$, belum tergerak untuk ikut mempraktikkannya walau hanya sekedar untuk latihan.

Dalam hal pemahaman terhadap kelebihan dan kelemahan teknik okulasi yang digunakan untuk mengembangbiakkan tanaman buah, ternyata sebagian besar anggota kelompok tidak mengetahuinya. Setelah dilakukan pelatihan, walaupun tidak semuanya paham dan hanya sepertiga yang sangat paham, terlihat bahwa separuh dari anggota kelompok bisa mengerti sedikit tentang kelebihan dan kelemahan teknik okulasi. Ihsan dan Sukarmin (2011) menyebutkan bahwa cara perbanyakan yang umum dilakukan pada tanaman rambutan adalah cangkok dan okulasi. Namun kedua cara tersebut mempunyai beberapa kelemahan. Cara okulasi kelemahannya adalah tidak dapat dilakukan setiap saat, karena hanya bisa dilakukan pada saat batang atas dan batang bawah mudah dikelupas kulitnya dan tingkat keberhasilannyapun relatif rendah, tergantung pada keahlian pelaku dan kondisi peralatannya. Widodo, dkk (2015) menjelaskan tentang kelebihan okulasi yaitu merupakan salah satu teknik perbanyakan tanaman secara vegetatif yang bertujuan untuk menghasilkan bibit tanaman buah dalam jumlah besar dan mempunyai kesamaan sifat dengan tanaman induk yang dipakai sebagai entres. Dengan mengetahui kelemahan dan kelebihan teknik perbanyakan tanaman buah secara okulasi ini, diharapkan anggota kelompok dapat meminimalkan akibat dari kelemahan teknik okulasi dan dapat memaksimalkan kelebihannya. Hal ini sangat penting mengingat bahwa salah satu tujuan memperbanyak pohon buah rambutan kelengkeng ini adalah agar kualitasnya sama dengan yang sudah ada, dalam arti tidak mengalami perubahan sifat ke arah yang kurang baik.

Beralih pada pertanyaan untuk menggali pengetahuan anggota kelompok tentang kebutuhan batang bawah yang diperlukan untuk melakukan okulasi, terlihat bahwa separuh anggota kelompok tidak mengetahui caranya (Tabel 4). Namun setelah diadakan pelatihan, semua menjadi paham perihal menyiapkan batang bawah. Pemahaman ini sangat penting, karena diharapkan semua anggota kelompok nantinya mampu menyediakan sendiri batang bawah untuk okulasi.

Pada okulasi hijau tanaman karet, batang bawah merupakan tanaman penopang yang berfungsi sebagai sumber pemasok nutrisi bagi batang atas (Wahid, 2011; Siagian, 2012 dalamRusli dkk., 2014). Jelaslah bahwa perlu dilakukan pemilihan batang bawah yang cukup umur, sehat, dan kuat. Tanaman yang dijadikan batang bawah umumnya diperoleh dari hasil perbanyakan biji yang memiliki 
pertumbuhan kuat serta memiliki sistem perakaran kokoh dan relatif tahan terhadap kekeringan.

Dalam hal pengetahuan tentang mata tempel untuk okulasi, semua anggota kelompok bisa dikatakan belum mengetahui ciri ciri mata tempel yang baik. Namun setelah dilakukan pelatihan, ternyata sebagian besar mereka merasa telah memahami ciri-ciri mata tempel yang baik untuk okulasi. Pemahaman ini penting karena mereka sendiri kelak harus menyiapkan mata tempel dari pohon rambutan kelengkeng yang tentunya ada banyak sekali mata tunasnya dengan berbagai kondisi fisiologis. Dalam pelatihan memang ditunjukkan contoh mata tempel yang baik dan yang tidak baik, agar kelak anggota kelompok bisa memilih mata tempel yang baik, sehingga bisa menghemat tenaga, watu dan biaya. Suharsi dan Sari (2013) menyebutkan bahwa umur batang bawah mempengaruhi proses pertautan antara batang atas dan batang bawah. Hasil penelitian Ihsan dan Sukarmin (2011) pada okulasi tanaman rambutan menunjukkan bahwa persentase okulasi jadi tertinggi $(88,8 \%)$ diperoleh pada batang bawah umur 5 bulan (perlakuan A) dan terendah $(68,8 \%)$ pada batang bawah umur 9 bulan (perlakuan B). Sukarmin (2010) menyatakan, luka sayatan pada batang bawah yang berumur relatif muda lebih cepat sembuh dan menyatu dengan entres dibanding yang umurnya lebih tua.

Dalam hal pemahaman tentang tahapan melakukan okulasi dan penyebab kegagalannya ternyata hampir semua anggota belum paham benar dan

Tabel 4 Pemahaman anggota kelompok dalam menyiapkan batang bawah dan mata tempel

\begin{tabular}{|c|c|c|c|c|c|c|}
\hline \multirow[b]{2}{*}{$\begin{array}{c}\text { MATERI } \\
\text { PERTANYAAN }\end{array}$} & \multicolumn{3}{|c|}{ Sebelum Pelatihan } & \multicolumn{3}{|c|}{ Setelah Pelatihan } \\
\hline & $\begin{array}{c}\% \\
\text { Tidak } \\
\text { tahu }\end{array}$ & $\begin{array}{c}\% \\
\text { Tahu } \\
\text { sedikit }\end{array}$ & $\begin{array}{c}\% \text { sangat } \\
\text { Mengetahui }\end{array}$ & $\begin{array}{c}\% \\
\text { Tidak } \\
\text { tahu }\end{array}$ & $\begin{array}{c}\% \\
\text { Tahu } \\
\text { sedikit }\end{array}$ & $\begin{array}{c}\% \\
\text { sangat } \\
\text { Mengetahui }\end{array}$ \\
\hline \multirow[t]{2}{*}{$\begin{array}{l}\text { Apakah anda } \\
\text { mengetahui cara } \\
\text { menyiapkan } \\
\text { batang bawah }\end{array}$} & 50,00 & 50,00 & 0,00 & 0,00 & 25,00 & 75,00 \\
\hline & \multicolumn{3}{|c|}{ Sebelum Pelatihan } & \multicolumn{3}{|c|}{ Setelah Pelatihan } \\
\hline $\begin{array}{c}\text { MATERI } \\
\text { PERTANYAAN }\end{array}$ & $\begin{array}{c}\% \\
\text { Tidak } \\
\text { tahu }\end{array}$ & $\begin{array}{c}\% \\
\text { Tahu } \\
\text { sedikit }\end{array}$ & $\begin{array}{c}\% \text { sangat } \\
\text { Mengetahui }\end{array}$ & $\begin{array}{c}\% \\
\text { Tidak } \\
\text { tahu }\end{array}$ & $\begin{array}{c}\% \\
\text { Tahu } \\
\text { sedikit }\end{array}$ & $\begin{array}{c}\% \\
\text { sangat } \\
\text { Mengetahui }\end{array}$ \\
\hline \multirow[t]{2}{*}{$\begin{array}{l}\text { Apakah anda } \\
\text { mengetahui ciri2 } \\
\text { mata tempel yg } \\
\text { baik }\end{array}$} & 83,33 & 16,67 & 0,00 & 0,00 & 25,00 & 75,00 \\
\hline & \multicolumn{3}{|c|}{ Sebelum Pelatihan } & \multicolumn{3}{|c|}{ Setelah Pelatihan } \\
\hline $\begin{array}{c}\text { MATERI } \\
\text { PERTANYAAN }\end{array}$ & $\begin{array}{c}\% \\
\text { Tidak } \\
\text { tahu }\end{array}$ & $\begin{array}{c}\% \\
\text { Tahu } \\
\text { sedikit }\end{array}$ & $\begin{array}{c}\% \\
\text { sangat } \\
\text { Mengetahui }\end{array}$ & $\begin{array}{c}\% \\
\text { Tidak } \\
\text { tahu }\end{array}$ & $\begin{array}{c}\% \\
\text { Tahu } \\
\text { sedikit }\end{array}$ & $\begin{array}{c}\% \\
\text { sangat } \\
\text { Mengetahui }\end{array}$ \\
\hline $\begin{array}{l}\text { Apakah anda } \\
\text { mengetahui ciri2 } \\
\text { kapan umur } \\
\text { tanaman bs } \\
\text { diokulasi baik } \\
\text { batang } \\
\text { bawah/batang atas }\end{array}$ & 75,00 & 25,00 & 0,00 & 0,00 & 41,67 & 58,33 \\
\hline
\end{tabular}

Sumber: Data Primer (2016) 
sebagian kecil hanya mengetahui sedikit tentang tahapan okulasi. Namun setelah dilakukan pelatihan, separuh dari anggota kelompok sangat paham dengan tahapan okulasi dan penyebab kegagalannya. Rohmaningtyas (2010) menyebutkan sejumlah faktor yang menyebabkan kegagalan okulasi diantaranya adalah:

- Batang atas atau bawah kotor (pada saat pengelupasan)

- Kambium batang bawah hilang karena saat pengelupasan sulit dan terlalu lama.

- Irisan tidak halus karena pisau kurang tajam

- Ikatan kurang kuat

- Terserang penyakit

- Kecepatan kerja

- Kalah dengan tunas baru yang tumbuh pada batang bawah.

Selain itu Rohmaningtyas (2010) juga menyebutkan bahwa pelaksanaan okulasi sangat baik dilakukan pada bulan September - Oktober (akhir musim kemarau) karena jika musim penghujan, terlalu banyak air menyebabkan okulasi membusuk, timbul bakteri, dan tumbuh jamur. Okulasi dilakukan pada jam 10 atau jam 16 untuk menempelkan kambium dan kulit kayu. Penempelan akan lebih erat bila kambium dalam keadaan kental.
Kaitannya dengan persiapan media tanam, hasil penelitian Suharsi dan Sari (2013) menunjukkan bahwa media tanam dengan komposisi tanah:arang sekam:kascing [1:1:1] (v:v:v) merupakan media terbaik untuk keberhasilan okulasi dan pertambahan panjang tunas jeruk keprok. Walaupun jenis tanamannya tidak sama, namun referensi ini bisa digunakan oleh kelompok untuk menyiapkan media tanam yang bisa mendukung keberhasilan okulasi. Dalam pelatihan ini batang bawah disiapkan dalam polybag, untuk tujuan kepraktisan pemeliharaan. Hasil penelitian (Rusli dkk, 2014) menunjukkan ukuran polybag berpengaruh positif terhadap pertumbuhan batang bawah tanaman karet umur 6 bulan setelah tanam. Semakin besar ukuran polybag (30 × 20-40 × $20 \mathrm{~cm})$, semakin baik pertumbuhan batang bawah. Media tumbuh bibit yang terdiri dari tanah dengan pupuk kandang sapi dengan perbandingan 1:1 menghasilkan pertumbuhan batang bawah serta persentase keberhasilan okulasi hijau tanaman karet yang tertinggi. Tidak terdapat interaksi yang nyata antara ukuran polybag dan media tumbuh terhadap pertumbuhan batang bawah dan keberhasilan okulasi hijau.

Pemahaman terakhir dalam okulasi adalah tentang tanda-tanda keberhasilan dari okulasi

Tabel 5 Pemahaman anggota kelompok terhadap tahapan okulasi dan penyebab kegagalannya

\begin{tabular}{|c|c|c|c|c|c|c|}
\hline \multirow{4}{*}{$\begin{array}{c}\text { MATERI } \\
\text { PERTANYAAN }\end{array}$} & \multicolumn{3}{|c|}{ Sebelum Pelatihan } & \multicolumn{3}{|c|}{ Setelah Pelatihan } \\
\hline & $\%$ & $\%$ & $\%$ & $\%$ & $\%$ & $\%$ \\
\hline & Tidak & Tahu & sangat & Tidak & Tahu & sangat \\
\hline & tahu & sedikit & Mengetahui & tahu & sedikit & Mengetahui \\
\hline $\begin{array}{l}\text { Apakah } \\
\text { mengetahui } \\
\text { tahapan melakukan } \\
\text { okulasi }\end{array}$ & 83,33 & 16,67 & 0,00 & 0,00 & 33,33 & 66,67 \\
\hline \multirow{4}{*}{$\begin{array}{c}\text { MATERI } \\
\text { PERTANYAAN }\end{array}$} & \multicolumn{3}{|c|}{ Sebelum Pelatihan } & \multicolumn{3}{|c|}{ Setelah Pelatihan } \\
\hline & $\%$ & $\%$ & $\%$ & $\%$ & $\%$ & $\%$ \\
\hline & Tidak & Tahu & sangat & Tidak & Tahu & sangat \\
\hline & tahu & sedikit & Mengetahui & tahu & sedikit & Mengetahui \\
\hline Apakah anda & 83,33 & 16,67 & 0,00 & 0,00 & 50,00 & 50,00 \\
\hline mengetahui & & & & & & \\
\hline penyebab & & & & & & \\
\hline kegagalan dalam & & & & & & \\
\hline melakukan okulasi & & & & & & \\
\hline
\end{tabular}

Sumber: Data Primer (2016) 
dan cara merawatnya. Dalam hal ini hampir semua anggota kelompok tidak memahami kapan okulasi perlu diperiksa dan apa saja tanda keberhasilan okulasi itu. Namun setelah dilakukan pelatihan walaupun belum semua paham betul, namun sudah tidak ada anggota kelompok yang merasa belum mengetahui. Widodo dkk (2015) Salah satu faktor yang mempengaruhi keberhasilan okulasi yaitu kompabilitas antara batang bawah dan entres (batang atas). Pada umumnya batang atas dan batang bawah dari kultivar sama akan menghasilkan tempelan yang kompatibel (kecocokan antara batang bawah dan entres sehingga okulasi dapat tumbuh dengan baik).

Rusli dkk (2014) membuat Kriteria keberhasilan okulasi adalah apabila pada saat pengamatan mata tempel entres berwarna hijau. Ihsan dan Sukarmin (2011) menyebutkan pemeliharaan tanaman yang telah diokulasi meliputi penyiraman, pemangkasan, penyiangan gulma, dan pengendalian hama penyakit. Penyiraman dilakukan hanya pada media tanam. Tunas-tunas yang muncul selain pada bidang okulasi dibuang dan gulma yang tumbuh dicabut. Hama dan penyakit dikendalikan dengan pestisida atau secara manual dengan tangan untuk hama yang dapat ditangkap.

Tujuan utama pelatihan memang untuk memberikan pengetahuan sekaligus ketrampilan terhadap para peserta. Disadari bahwa pengetahuan maupun ketrampilan yang telah diperoleh harus ditingkatkan melalui kegiatan praktis secara mandiri. Tentu saja pencapaian masing masing peserta akan sangat berbeda tergantung oleh berbagai sebab. Untuk menjaga keberhasilan dan kesinambungan transfer pengetahuan dan teknologi ini, sangat diperlukan adanya pendampingan dan kaderisasi.

\section{KESIMPULAN}

1. Beberapa jenis tanaman buah yang potensi dikembangkan di desa Karangrejo antara lain adalah rambutan, pisang dan nangka. Buah Rambutan kelengkeng mempunyai karakter yang unggul baik dalam hal rasa, ketebalan

Tabel 6 Pemahaman anggota kelompok terhadap tanda keberhasilan okulasi dan perawatannya

\begin{tabular}{|c|c|c|c|c|c|c|}
\hline \multirow[b]{2}{*}{$\begin{array}{c}\text { MATERI } \\
\text { PERTANYAAN }\end{array}$} & \multicolumn{2}{|c|}{ Sebelum Pelatihan } & \multicolumn{4}{|c|}{ Setelah Pelatihan } \\
\hline & $\begin{array}{c}\% \\
\text { Tidak } \\
\text { tahu }\end{array}$ & $\begin{array}{c}\% \\
\text { tahu }\end{array}$ & & $\begin{array}{c}\% \\
\text { Tidak } \\
\text { tahu }\end{array}$ & $\begin{array}{c}\% \\
\text { tahu }\end{array}$ & \\
\hline $\begin{array}{l}\text { Apakah anda } \\
\text { mengetahui kapan } \\
\text { balutan okulasi } \\
\text { dibuka untuk } \\
\text { melihat } \\
\text { keberhasilannya }\end{array}$ & 91,67 & 8,33 & & 0,00 & 100,00 & \\
\hline \multirow[b]{2}{*}{$\begin{array}{c}\text { MATERI } \\
\text { PERTANYAAN }\end{array}$} & \multicolumn{3}{|c|}{ Sebelum Pelatihan } & \multicolumn{3}{|c|}{ Setelah Pelatihan } \\
\hline & $\begin{array}{c}\% \\
\text { Tidak } \\
\text { tahu }\end{array}$ & $\begin{array}{c}\% \\
\text { Tahu } \\
\text { sedikit }\end{array}$ & $\begin{array}{c}\% \\
\text { sangat } \\
\text { Mengetahui }\end{array}$ & $\begin{array}{c}\% \\
\text { Tidak } \\
\text { tahu }\end{array}$ & $\begin{array}{c}\% \\
\text { Tahu } \\
\text { sedikit }\end{array}$ & $\begin{array}{c}\% \\
\text { sangat } \\
\text { Mengetahui }\end{array}$ \\
\hline $\begin{array}{l}\text { Apakah anda } \\
\text { mengetahui tanda } \\
\text { keberhasilan } \\
\text { okulasi dan cara } \\
\text { merawatnya }\end{array}$ & 83,33 & 16,67 & 0,00 & 0,00 & 50,00 & 50,00 \\
\hline
\end{tabular}


daging, aroma, kemudahan mengelupas ("nglotok") dan tidak cepat rusak.

2. Adanya pelatihan teknik okulasi telah meningkatkan pemahaman dan ketrampilan anggota kelompok dalam hal menyiapkan batang bawah, mata tempel, menyiapkan bahan dan alat, melakukan okulasi, memantau keberhasilan okulasi dan merawat okulasi.

\section{DAFTAR PUSTAKA}

Afrina, NH. 2012. Pembuatan dan Analisa Selai Rambutan Dengan Penambahan Kelopak Bunga Rosela (Hibiscus sabdariffa L.). Kementrian Perindustrian RI Pusat Pendidikan dan Pelatihan Industri Sekolah Menengah Kejuruan (SMK SMAK Padang.

Anonim. 2012. Monografi Desa Karangrejo. Pemerintah Desa Karangrejo, Kecamatan Borobudur, Kabupaten Magelang.

Duhclun I., Arinong AR., Nilawati E. 2006. Analisis Usahatani Rambutan (Nephelium lappaceum L) Terhadap Peningkatan Pendapatan Petani. Jurnal Agrisistem, Juni 2006, Vol 2 No. 1: 40-45.

Hastuti S., Kurnianti YD., Fakhry M. 2013. Produksi Manisan Rambutan kering Dengan Variasi Konsentrasi Larutan Kapur dan Karakteristik Pengeringan. AGROINTEK Volume 7, No.1: 38-42.

Ibrahim A., Adiputra YT., Setyawan A., Hudaidah S. 2013. Potensi Ekstrak Kulit Buah dan Biji Rambutan (Nephelium lappaceum L) sebagai Senyawa Anti Bakteri Patogen Pada Ikan. e-Jurnal Rekayasa dan Teknologi Budidaya Perairan Volume I No 2 Februari 2013: 135-144.

Ihsan F dan Sukarmin. 2011. Teknik Pengujian Umur Batang Bawah terhadap Keberhasilan dan Pertumbuhan Rambutan Hasil Okulasi. Buletin Teknik Pertanian Vol. 16, No. 1, 2011: 28-30.
Issara, U., Zzaman, W., Yang, T.A. 2014. Rambutan seed fat as a potential source of cocoa butter substitute in confectionary product. International Food Research Journal 21(1): 25-31.

Kusminingrum, N. 2008. Potensi Tanaman dalam Menyerap CO2 untuk Mengurangi Dampak Pemanasan Global. Jurnal Pemukiman Vol 3 (2): 96-105.

Lesmayati S. 2014. Pascapanen: Sirup Buah Rambutan. BPTP Kalimantan Selatan. http://kalsel.litbang.pertanian.go.id/ind/i n $\mathrm{d}$ ex $\cdot \mathrm{php}$ ? option $=\mathrm{com} \mathrm{m}_{-} \mathrm{cont}$ ent \& vi e w $=$ article $\&$ id $=336$ : pascapanen $\&$ catid $=14$ : alsin $\&$ Itemid $=43$. Diakses tanggal 5 Agustus 2016.

Rahayu L., Zakir L., Keban SA. 2013. The Effect of Rambutan Seed (Nephelium lappaceumL.) Infusion on Blood Glucose and Pancreas Histology of Mice Induced with Alloxan. Jurnal Ilmu Kefarmasian Indonesia, April 2013, hlm. 28-35

Rohmaningtyas D. 2010. Perbanyakan Tanaman Mangga Dengan Teknik Okulasi di Kebun Benih Tanaman Pangan dan Hortikultura Tejomantri Wonorejo Polokarto Sukoharjo. Tugas Akhir Program DIII Fakultas Pertanian Universitas Sebelas Maret Surakarta.

Rosahdi TD., Kusmiyati M., Wijayanti FR. 2013. Uji Aktivitas Daya Antioksidan Buah Rambutan Rapiah dengan metode DPPH. Jurnal ISTEK Vol.7 No 1. http:// journal.uinsgd.ac.id/index.php/istek/issue/ view/40. Diakses tgl 5 Agustus 2016.

Rusli., Heryana N., Saefudin. 2014. Pertumbuhan Batang Bawah dan Keberhasilan Okulasi Hijau Tanaman Karet Pada beberapa Ukuran Polybag dan Media Tumbuh Yang Berbeda. J. TIDP 1(3), 141-148November, 2014. 
Sofianto, A. 2013. Peran Kelompok Masyarakat Dalam Penguatan Inovasi Sosial di Desa Karangrejo, Kecamatan Borobudur, Kabupaten Magelang. Jurnal Litbang Provinsi Jawa Tengah, Vol 11, No. 1: 75-86.

Suharsi, TK dan Sari, ADP. 2013. Pertumbuhan Mata Tunas Jeruk Keprok (Citrus nobilis) Hasil Okulasi pada Berbagai Media Tanam dan Umur Batang Bawah Rough Lemon (C. Jambhiri). Jurnal Ilmu Pertanian Indonesia (JIPI), Agustus 2013 Vol. 18 (2): 97-101ISSN 0853-4217.
Sukarmin. 2010. Teknik sambung dini pada durian (Durio zibethinus). Makalah Temu Teknis Jabatan Fungsional Non-Peneliti, Bogor, 12-13 Oktober 2010.

Widodo W., Arifin SZ., Asmuris MR. 2015. Keberhasilan Okulasi Tiga Kultivar Kelengkeng Pada Ruas Batang Yang Berlainan. Proseding Seminar Nasional Universitas PGRI. ISBN 978-602-73690-3-0. 
